FACULTY OF ECONOMICS AND APPLIED ECONOMIC SCIENCES

CENTER FOR ECONOMIC STUDIES

ENERGY, TRANSPORT \& ENVIRONMENT

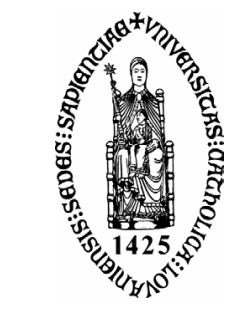

KATHOLIEKE UNIVERSITEIT

LEUVEN

WORKING PAPER SERIES

$n^{\circ}$ 2004-09

\title{
Imperfect competition and congestion in the City
}

A. de Palma (Member of the Institut Universitaire de

France, THEMA, Université

de Cergy-Pontoise, France and CORE, Belgium)

S. Proost (K.U.Leuven - CES)

August 2004

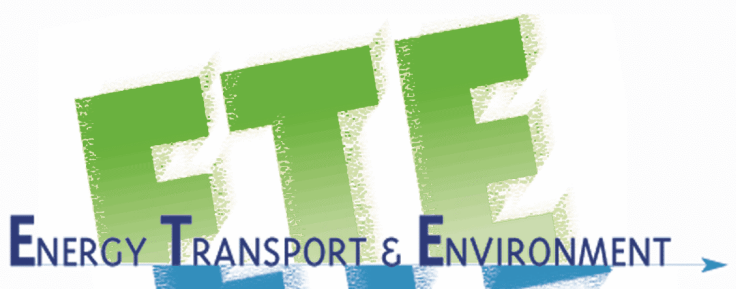

secretariat:

Isabelle Benoit

KULeuven-CES

Naamsestraat 69, B-3000 Leuven (Belgium)

tel: $\quad+32(0) 1632.66 .33$

fax: $\quad+32(0) 1632.69 .10$

e-mail: Isabelle.Benoit@econ.kuleuven.ac.be

http://www.kuleuven.be/ete 


\title{
Imperfect competition and congestion in the City
}

\author{
André de Palma and Stef Proost* \\ July, 2003, Revised May,2004 ${ }^{\dagger}$
}

\begin{abstract}
This paper presents a spatial model to study imperfect competition with congestion. The model is used to examine the price and wage setting of subcenters of a city. Residents live in a city while they shop and work in subcentres. Each subcenter offers one differentiated product and one differentiated workplace. Shopping and commuting from the city to the subcenter requires the use of transport infrastructure that can be congested. We show the existence of a Nash equilibrium in prices and wages and analyse the welfare impacts of congestion charging and infrastructure policies. This paper generalises the literature on imperfect competition with differentiated products as well as the literature on congestion pricing with imperfect competition.

Keywords: Road Pricing, Product Differentiation, Location Theory, New Economic Geography, Congestion.

JEL: L13, D43, R41, R3

\footnotetext{
*André de Palma: Member of the Institut Universitaire de France, THEMA, Université de Cergy-Pontoise, France and CORE, Belgium. Stef Proost, Center for Economic Studies, Catholic University of Leuven and CORE, Belgium. Correspondence to stef.proost@econ.kuleuven.ac.be //CES-KULeuven, Naamse straat 69, 3000 Leuven, Belgium, Tel +3216326801 Fax +3216326796

†We would like to thank Fay Dunkerly and Jacques Thisse for their suggestions on an early version of this paper.
} 


\section{Introduction}

This paper presents a model to study imperfect competition with congestion. We use this model to study the price and wage setting as well as the equilibrium number of differentiated shopping and workplace subcentres. Urban residents live and work in the center, while they also work and buy differentiated goods in subcenters. The shopping centers hire workers with differentiated disutilities of work and import intermediate goods from the center. Shoppers, workers and trucks share the same congested road infrastructure from the center to each of the shopping centers. There is only one producer per subcentre and he maximizes profit. He makes decisions on the price of his differentiated good variety and on the wage he needs to offer to attract workers. Lowering his price attracts more customers but also generates many more effects in this model. More customers means more congestion by shoppers, forces the firm to hire more workers and this requires higher wages. In addition, more workers also create more congestion and more customers also require more deliveries by trucks that have also become more expensive because of congestion.

We analyse the non-cooperative equilibrium in prices for this type of economy using a general equilibrium setting and a logit representation for the differentiated goods. The existence and welfare effects of equilibria with and without congestion are analysed. The effect of congestion and infrastructure charging policies on the price and wage setting and on the equilibrium number of subcenters is studied too.

Our model can be compared to three strands of the literature: the imperfect competition literature, the literature on congestion pricing with imperfect competition and the literature on the endogenous location of shopping centers. Our model uses the logit model to represent differentiated goods. Compared to the traditional models of imperfect competition (surveyed in [8]), our model offers two additional features. First, it examines imperfect competition in a general equilibrium framework as the labour market and the delivery of intermediate goods are explicitly modelled. Second, our model introduces congestion. Both elements will be shown to have an important effect on the imperfect equilibrium outcome. Introducing a general equilibrium framework and a differentiated job market offers much more complexity as firms compete on two markets rather than one. The equilibrium mark-up and the equilibrium number of firms are shown to be increasing in the product and job heterogeneity parameters. Congestion adds another component to the equilibrium mark-up because congestion acts as a disincentive to cut prices. The welfare economics of the number of firms also changes as we now have two market imperfections that interact. Congestion (and market power) can be relieved by having congestion pricing, by having more subcentres but also by having larger road infrastructure. The three strategies are to some extent substitutes.

The interplay between congestion and imperfect competition has already been covered in the case of homogenous goods for a monopoly by [7], and for a duopoly by [6].They show that the optimal congestion charge is smaller than the Pigouvian charge and that the homogenous good case can lead to multiple 
equilibria in the case of a duopoly. We generalise this literature in three ways. First we use a general equilibrium framework with shopping, commuting and delivery trafffic where the three types of traffic are influenced by the strategy of the monopsonist firm. Second we study the case of differentiated rather than homogenous goods and finally we allow for any number of competitors on the market.

Fujita and Thisse ([5] p. 221) survey shopping center models. These models study the endogenous location of shops and employment centers as well as consumers in a linear or homogenous space. Shopping centres may exist because of search costs or when they offer sufficiently differentiated products. Our model has a different focus: the location of consumers is given (they reside in the city center), the possible locations of subcenters are given ex-ante and every subcenter has only one producer that offers a given variety of the good. This means that we do not aim to study the origin, location or composition of subcenters, instead we limit ourselves to the study of the properties of the competition between different subcenters.

In the model interpretation we follow in this paper, we have residents that live in the city center but shop at and commute to subcenters. This is not necessarily the most common urban structure (see [1]). Our generic model allows an alternative interpretation. In this alternative interpretation, households choose a subcenter to reside in (they "shop" for a residence) and they work in the city and in another subcenter.

In sections 2 and 3 we develop the model structure. In sections 4 and 5 we study the equilibrium and the optimum without congestion. In sections 6 and 7 , we deal with the equilibrium and optimum with congestion. In section 7 we discuss the potential and interaction of three types of policies: road congestion charging, limiting the number of subcenters by a levy per subcenter and extending the capacity of the roads. Section 8 concludes with a simple numerical illustration.

\section{The model setting}

We consider a center, and $n$ subcenters. Residents are located in the center and consume a differentiated good and a homogeneous good. They supply differentiated labor as well as homogeneous labor. Each resident is active and provides the same amount of work. The homogeneous good is produced competitively in the center using homogeneous labor and requires no transport costs. We focus our attention on the production and the consumption of the differentiated good. There are $n$ differentiated goods with subcenter $i$ producing the quantity $D_{i}$.such that $D=\sum_{i=1 \ldots n} D_{i}$ In each subcenter, one producer offers one variety of the good (e.g. due to increasing returns to scale), hires heterogeneous labor, uses the homogeneous good as intermediary input and sells his product at the factory gates. We denote by $t_{i}$ the travel time between the center and subcenter $i$ (distance divided by speed) per trip. Households commute to subcenter $i$ to supply labour with a travel time of $\alpha^{w} t_{i}$, where $\alpha^{w}$ denotes the number of trips 
per unit of labour. Households also make shopping trips to subcenter $j$ with a travel time $\alpha^{d} t_{j}$, per unit of differentiated good, where $\alpha^{d}$ denotes the number of shopping trips per unit of consumption, for $i, j=1, . . n$. These two trips are treated as independent (trip chaining is not considered here). The intermediary (homogenous) goods needed in the subcenters are transported from the center to the subcenter with a travel time per unit of intermediary good of $\alpha^{h} t_{i}$, where $\alpha^{h}$ denotes the number of freight trips per unit of production. We first neglect congestion; in this case transportation cost $t_{i}$ is independent of the number of drivers using the road. Later, we treat congestion by recognizing that the transportation cost increases with the number of cars and trucks and decreases with road capacity.

\subsection{The production possibilities}

There are $N$ households who all work and each household supplies a fixed amount, $(1+\theta)$ units of labour time. The production of one unit of the differentiated good requires one unit of labour time. The remaining labour time of the household $\theta$ is devoted to the production of the homogeneous good. Each worker household consumes one unit of the differentiated good, the rest of his income is spent on the homogenous good.

We assume linear production technologies. The homogeneous good is produced using labour in a one to one ratio (one unit of the homogeneous good is produced during one unit of time). The homogeneous good is either consumed directly or used as input for the differentiated good and for the transport services (fixed and variable input). The production of the differentiated good in subcenter $i$ requires a fixed set-up cost $F$ (in the form of inputs of the homogeneous good) per subcenter and an intermediate input equal to $c^{1}$ units of the homogeneous good per unit of the differentiated good. Moreover, each subcenter requires some road infrastructure. The production of this road infrastructure requires $K$ units of the homogeneous good. The total consumption of the homogeneous good is denoted by $G$.

We can present the total production possibilities of the economy by comparing the net inputs and the total uses of the homogeneous good. We have the following identity for the supply and the demand for labour:

$$
(1+\theta) N=D+c^{1} D+n F+\left(\alpha^{w}+\alpha^{d}+\alpha^{h}\right) \sum_{i=1 \ldots n} t_{i} D_{i}+n K+G,
$$

where the LHS represents the total supply of labour. The first term in the RHS represents the direct use of labour in the production of the differentiated good ( $D$ with $D=N)$ ) while the remaining terms represent the use of the homogeneous good as input into the production of the differentiated good $\left(c^{1} D+n F\right)$, to pay for the transportation costs $\left(\alpha^{w}+\alpha^{d}+\alpha^{h}\right) \sum_{i=1 \ldots n} t_{i} D_{i}$ and to pay for the infrastructure cost $n K$. The remaining production of the homogeneous good $(G)$ is used as the final consumption good by the household.. 
The total consumption of the homogeneous good, $G$, is residual and given by:

$$
G=\theta N-c^{1} D-\left(\alpha^{w}+\alpha^{d}+\alpha^{h}\right) \sum_{i=1 \ldots n} t_{i} D_{i}-n(F+K) .
$$

In the symmetric case (considered in most of this paper), $t_{i}=t, i=1 \ldots n$ and the average individual consumption of homogeneous good $g(n)$ wkere there are $n$ subcenters, is given by:

$$
g(n)=\theta-c^{1}-\left(\alpha^{w}+\alpha^{d}+\alpha^{h}\right) t-n(F+K) / N .
$$

Note that at least one center (center 1) is sustainable provided that:

$$
g(1)=\theta-c^{1}-\left(\alpha^{w}+\alpha^{d}+\alpha^{h}\right) t-(F+K) / N>0 .
$$

\subsection{Market structures and taxes}

The homogenous good is produced competitively in the center. The wage in this industry is normalized to one. As the market is competitive and marginal cost is equal to one, the price of the homogenous good is also one (in this case, the transport cost is not incurred by the producers of the homogeneous good). As a consequence, the value of time is one $^{1}$ and the transport cost equals the travel time, $t_{i}$.

The price of the differentiated good $i$ is denoted by $p_{i}$ and the wage offered by firm $i$ producing the differentiated good $i$ is denoted by $w_{i}, i=1 \ldots n$. The government finances the public infrastructure input by imposing a head-tax $T$ and a fixed levy on the firms $S: n K=N T+n S$.

\subsection{Household preferences}

The household consumes the homogeneous good (at the city center) and one unit of the differentiated good in one of the $n$ subcenters. Each household supplies $\theta$ units of labour in the city center for the production of the homogeneous good and one unit of labour in one subcenter for the production of the differentiated good. As labour supply is fixed, and as the quantity of the differentiated good is also fixed, the consumption of the homogeneous good is the residual. We consider that each household chooses a single place of employment (besides the city center) and a single shopping destination (besides the city center). Therefore the only choice of interest for the household is the choice of the employment location (where the differentiated good is produced) and the choice of the type of differentiated good to consume (where to shop).

The direct utility function of a household who supplies one unit of labour to the differentiated industry $i$ and buys one unit of the differentiated good of type $k$ is:

\footnotetext{
${ }^{1}$ One unit of time allows the production of one unit of the homogeneous good, which has a price equal to one, so the opportunity cost of one unit of time spent on the road is one.
} 


$$
V_{i k}=g_{i k}+\widetilde{h}_{k}-\widetilde{\beta}_{i}-\beta \theta,
$$

where $g_{i k}$ represents the consumption of the homogenous good (whose marginal utility is one), $\widetilde{h}_{k}$ is the direct utility of the consumption of one unit of the differentiated good $k, \widetilde{\beta}_{i}$ is the disutility of labour in sub-center $i$ and $\beta$ is the disutility of labour in the center.

We assume that households have an equal share of the total profit, $\sum_{l=1 \ldots n} \pi_{l}$ and that the profit share is small. As a consequence, consumers take the profits as given and the owner of a differentiated firm does not take into account the impact of his pricing policy on his utility as a consumer or as a worker. ${ }^{2}$ The household budget constraint is

$$
\left(w_{i}-\alpha^{w} t_{i}\right)+\theta+\frac{1}{N} \sum_{l=1 \ldots n} \pi_{l}=\left(p_{k}+\alpha^{d} t_{k}\right)+g_{i k}+T .
$$

According to identity (4), the revenue from supplying labour to subcenter $i$ minus the commuting cost plus the revenue from supplying labour to the center, plus the share in total profits is equal to the cost of consumption, including shopping cost, plus the cost of the homogeneous good plus the head tax. By substitution of the budget constraint in (3), we get the indirect utility function:

$$
U_{i k}=\left(w_{i}-\alpha^{w} t_{i}\right)-\widetilde{\beta}_{i}+\theta(1-\beta)+\widetilde{h}_{k}-\left(p_{k}+\alpha^{d} t_{k}\right)+\frac{1}{N} \sum_{l=1 \ldots n} \pi_{l}-T .
$$

To recognize the fact that the jobs in the differentiated industry are heterogeneous, we model the disutility of labour, $\widetilde{\beta}_{i}$ as a random variable:

$$
\widetilde{\beta}_{i}=\beta_{i}-\mu^{w} \varepsilon_{i}
$$

where $\mu^{w}>0$ is a scale parameter that measures employment heterogeneity and $\varepsilon_{i}$ are i.i.d. double exponentially distributed. ${ }^{3}$ The idiosyncratic terms $\varepsilon_{i}$ express the match values between the employments and the workers.

Similarly, the goods produced in the subcenter are differentiated from the shoppers perspectives. We assume that:

$$
\widetilde{h}_{k}=h_{k}+\mu^{d} \varepsilon_{k}
$$

where $\mu^{d}>0$ is a scale parameter and $\varepsilon_{i}$ are i.i.d. double exponentially distributed. ${ }^{4}$

\footnotetext{
${ }^{2}$ This way we avoid one of the major problems in general equilibrium with imperfect competition. For a survey see [3]

${ }^{3}$ The c.d.f. of the double exponential is $F(x)=\exp [-\exp (-x)]$.

${ }^{4}$ For symmetric distributions (such as for normal), this formulation is the same as $\widetilde{h}_{k}=$ $h_{k}-\mu^{d} \varepsilon_{k}$. Later on, we use double exponential distribution which lead to the Logit model with the specification (7). The specification $\widetilde{h}_{k}=h_{k}+\mu^{d} \varepsilon_{k}$, with double exponential distribution leads to the reverse Logit, which is subtantiallly less tractable (see, [9]), and therefore not considered here.
} 
We consider the symmetric case: $\beta_{i}=\beta, i=1 . . n$ (the centers are on average equally attractive from the worker perspective), $h_{k}=h, k=1$..n (all differentiated goods have the same gross benefit), and $t_{i}=t, i=1 \ldots n$ (all subcenter are equally far away). In this case, the conditional indirect utility (5) reduces to:

$$
U_{i k}=\Omega+w_{i}-p_{k}+\mu^{w} \varepsilon_{i}+\mu^{d} \varepsilon_{k},
$$

where:

$$
\Omega=-\left(\alpha^{w} t+\beta\right)+\theta(1-\beta)+h-\alpha^{d} t+(1 / N) \sum_{i=1 \ldots n} \pi_{l}-T .
$$

Note that this model requires information on the distribution of the match values $\left(\varepsilon_{i}\right.$ and $\left.\varepsilon_{k}\right)$. The precise value of the match value of a given household is unknown. In other words, the individuals are statistically independent and nothing changes in the model at the aggregate level if the match values were to change over time. As a consequence, the households are allowed to modify their employment choice and the shopping choices over time provided that this will not change the expected demand addressed to each firm and the expected number of workers hired by each firm.

\subsection{Profits of firms}

Recall that $D_{i}$ denotes the demand addressed to Firm $i$ (with $\sum_{i=1}^{n} D_{i}=N$ ), $w_{i}$ the wage offered by Firm $i$ and $p_{i}$ the price charged by Firm $i$ for one unit of the differentiated good. In the symmetric case, the marginal cost of intermediate inputs is $c=c^{1}+\alpha^{h} t, i=1 \ldots n$ (in the non-symmetric case, it is $c_{i}=c^{1}+\alpha^{h} t_{i}$, $i=1 \ldots n)$, and the marginal production cost is $c+w_{i}$. The profit of Firm $i$ is:

$$
\pi_{i}(w, p)=\left(p_{i}-w_{i}-c\right) D_{i}-(F+S),
$$

where $w=\left(w_{1}, \ldots, w_{n}\right)$ and $p=\left(p_{1}, \ldots, p_{n}\right)$ are the wage and the price vectors.

\section{Household choices}

\subsection{The labour market choices}

When a household is choosing in which subcenter $i$ to work, all the terms $\left(-p_{k}+\mu^{d} \varepsilon_{k}\right)$ are identical and therefore do not affect their choice of employment. Given the choice of location $\mathrm{k}$ for shopping, the utility of working in $\mathrm{i}$ becomes (see 8):

$$
U_{i \mid k}=\Omega_{k}+w_{i}+\mu^{w} \varepsilon_{i}
$$

where $\Omega_{k}=\Omega-p_{k}+\mu^{d} \varepsilon_{k}$. 
The probability that a worker chooses to commute to subcenter $i$ is

$P_{i \mid k}^{w}=\operatorname{Pr} o b\left\{U_{i \mid k} \geq U_{j \mid k}, j=1 \ldots n\right\}$. Note that the choice probabilities are independent of $k$ and can be written as $P_{i}^{w}$, with

$$
P_{i}^{w}=\operatorname{Pr} o b\left\{w_{i}+\mu^{w} \varepsilon_{i} \geq w_{j}+\mu^{w} \varepsilon_{j}, j=1 \ldots n\right\} .
$$

Using the fact that $\varepsilon_{i}$ are double exponentially distributed:

$$
P_{i}^{w}=\frac{\exp \left(\frac{w_{i}}{\mu^{w}}\right)}{\sum_{j=1 \ldots n} \exp \left(\frac{w_{j}}{\mu^{w}}\right)}, i=1 \ldots n .
$$

Therefore, the choice probabilities for the labor market have a logit type. Note that all the workers will select the job which offers the largest wage if the heterogeneity parameter $\mu^{w}$ is zero. Otherwise, a worker may accept a reduced wage in order to work for a firm which best fits his preferences. The average expected number of workers in subcenter $i$ is: $N P_{i}^{w}$.

\subsection{Consumer choices}

When a household is choosing in which subcenter $k$ to shop, all the terms $\left(w_{i}+\mu^{w} \varepsilon_{i}\right)$ connected with the choice of employment are identical and therefore do not affect their choice. In this case, we can rewrite the conditional utility of shopping in $\mathrm{k}$ given the choice of workplace i as (see 8) :

$$
U_{k \mid i}=\Omega_{i}-p_{k}+\mu^{d} \varepsilon_{k},
$$

where $\Omega_{i}=\Omega+w_{i}+\mu^{w} \varepsilon_{i}$. The probability that a household located in the center patronizes subcenter $k$ is $P_{k \mid i}^{d}=\operatorname{Pr} o b\left\{U_{k \mid i} \geq U_{l \mid i}, l=1 \ldots n\right\}$. As before, the choice probability $P_{k \mid i}^{d}$ is independent of the choice $i$ and denoted by $P_{k}^{d}$. We have $P_{k}^{d}=\operatorname{Pr} o b\left\{-p_{k}+\mu^{d} \varepsilon_{k} \geq-p_{l}+\mu^{d} \varepsilon_{l}, l=1 \ldots n\right\}$. With the double exponential distribution, we get:

$$
P_{k}^{d}=\frac{\exp \left(\frac{-p_{k}}{\mu^{d}}\right)}{\sum_{l=1 \ldots n} \exp \left(\frac{-p_{l}}{\mu^{d}}\right)}, k=1 \ldots n .
$$

\subsection{Market clearing conditions}

Recall that every household consumes one unit of the differentiated good and that the production of every unit of the differentiated good requires one unit of labour (provided by one household). Assuming that the labour market clears (wages are flexible), the fraction of workers which decides to work at subcenter $i$ must be equal to the fraction of shoppers which patronize subcenter $i$, whatever 
the wages and the prices, Thus $P_{i}^{w}=P_{i}^{d}$, where $P_{i}^{w}$ is given by (11) and $P_{i}^{d}$ is given by (12). We get a relation between the price $p_{i}$ and the wage $w_{i}$ set by Firm i:

$$
\frac{\exp \left(\frac{w_{i}}{\mu^{w}}\right)}{\sum_{j=1 \ldots n} \exp \left(\frac{w_{j}}{\mu^{w}}\right)}=\frac{\exp \left(\frac{-p_{i}}{\mu^{d}}\right)}{\sum_{j=1 \ldots n} \exp \left(\frac{-p_{j}}{\mu^{d}}\right)} .
$$

Therefore, the demand for the differentiated product sold in subcenter $i$ is $D_{i}=N P_{i}^{d}=N P_{i}^{w}$.

\section{Equilibrium without congestion}

\subsection{The profit function}

We look for a symmetric Nash equilibrium in prices and wages between firms (or subcenters). The strategic variables of subcenter $i$ are $w_{i}$ and $p_{i}$. Given the market clearing condition (13), the choice of $w_{i}$ determines the choice of $p_{i}$ and vice-versa.

Consider subcenter $i$ which takes all other wages and prices as given. Since the LHS of (13) is strictly increasing in $w_{i}$ and the RHS of this equation is strictly decreasing in $p_{i}$, there is a one to one relation between $w_{i}$ and $p_{i}$, the other prices and wages being fixed. Let $p_{i}=f_{i}\left(w_{i}\right)$. Note that $f_{i}\left(w_{i}\right)=f\left(w_{i}, w_{-i}, p_{-i}\right)$ where $w_{-i}$ and $p_{-i}$ are the vectors $w$ and $p$ with the $i^{\text {th }}$ component missing. We shall use the following result:

$$
\frac{d f_{i}\left(w_{i}\right)}{d w_{i}}=-\frac{\frac{P_{i}^{w}\left(1-P_{i}^{w}\right)}{\mu^{w}}}{\frac{P_{i}^{d}\left(1-P_{i}^{d}\right)}{\mu^{d}}}=-\frac{\mu^{d}}{\mu^{w}}<0 .
$$

This expression is negative since when a firm raises its wage, it increases the number of workers hired. In order to be able to sell the additional production, a firm needs to reduce its prices. The price reduction needs to be larger when $\mu^{d}$ is larger because then the consumers are more loyal to their ideal product. Conversely, the price reduction is smaller when $\mu^{w}$ is larger, since in this case the workers are more loyal to their preferred workplace and less amenable to changing jobs for a wage increase.

Given the relation between price and wage of Firm $i$, the profit of subcenter $i$ only depends on a single strategic variable (we select the wage as the strategic variable $)$. In this case $\pi_{i}\left(w_{i}, w_{-i}, f_{i}\left(w_{i}\right), p_{-i}\right)=\tilde{\pi}_{i}\left(w_{i}, w_{-i}, p_{-i}\right)$ with:

$$
\tilde{\pi}_{i}\left(w_{i}, w_{-i}, p_{-i}\right)=\left[f_{i}\left(w_{i}\right)-w_{i}-c\right] N P_{i}^{w}-(F+S),
$$

where we use the identity $D_{i}=N P_{i}^{w}$, and where $c=c^{1}+\alpha^{h} t$. 


\subsection{Short-run equilibrium}

Subcenters are competing in wages and prices in a non-cooperative Nash game. We wish to find the candidate symmetric equilibrium in prices and wages denoted by $\left(p^{e}, w^{e}\right)$. As shown above, the subcenters compete in either wage or price. We consider here that the strategic variable is the wage, $w_{i}$.

The best reply of subcenter $i$ to the wages and prices set by the other subcenters is:

$\frac{d \widetilde{\pi}_{i}\left(w_{i}, w_{-i}, p_{-i}\right)}{d w_{i}}=\left\{\left(\frac{d f_{i}\left(w_{i}\right)}{d w_{i}}-1\right)+\left(f_{i}\left(w_{i}\right)-w_{i}-c\right) \frac{\left(1-P_{i}^{w}\right)}{\mu^{w}}\right\} N P_{i}^{w}=0$.

Note that at the symmetric candidate equilibrium $P_{i}^{w}=P_{i}^{d}=1 / n$ and recall that $d f_{i}\left(w_{i}\right) / d w_{i}=-\mu^{d} / \mu^{w}$ Therefore (16), set at the symmetric candidate equilibrium, leads to:

$$
-\left(\frac{\mu^{d}}{\mu^{w}}+1\right)+\left(p^{e}-w^{e}-c\right) \frac{(n-1)}{n \mu^{w}}=0
$$

We prove in Appendix A that the candidate equilibrium is a Nash equilibrium. Therefore:

Proposition 1 In the absence of congestion, there exists a unique symmetric Nash equilibrium in prices and wages given by:

$$
p^{e}=c+w^{e}+\left(\mu^{d}+\mu^{w}\right) \frac{n}{(n-1)} .
$$

The equilibrium markup $p^{e}-\left(c+w^{e}\right)$ is increasing with product heterogeneity and with job heterogeneity. The role of product heterogeneity is well known (see [8]. The role of job heterogeneity is new: more job heterogeneity means that workers are also interested in other dimensions than the wage they earn (such as the proximity of the gym facility or the charms of the boss) so that wage differences become less important and this increases the profit margin. Interestingly, both types of heterogeneity work in the same direction and are additive. As in the standard model, the markup decreases when more firms compete in the market. However, the markup remains bounded away from zero as $n \rightarrow \infty$, as in the symmetric monopolistic competition models à la Chamberlin.

\subsection{Long-run equilibrium}

The equilibrium profit (see (15)) at the symmetric equilibrium is

$$
\pi^{e}=\left[p^{e}-w^{e}-c\right] \frac{N}{n}-(F+S)
$$

or after substitution of the equilibrium price levels (see Proposition 1): 


$$
\pi^{e}=\left(\mu^{d}+\mu^{w}\right) \frac{N}{(n-1)}-(F+S) .
$$

The profit is a decreasing function of the number of subcenters: further entry drives profits to zero.

In the long run, we assume that there is free entry or exit of subcenters. The long run equilibrium is such that the profit of each subcenter is zero (we neglect integer problems). The long-run $n^{f}$ number of subcenters is:

$$
n^{f}=1+\left(\mu^{d}+\mu^{w}\right) \frac{N}{F+S}>1 .
$$

At the free entry equilibrium, the consumption $g^{f}$ of the homogeneous good is:

$$
g^{f}=g(1)-\left(\mu^{d}+\mu^{w}\right) \frac{(F+K)}{(F+S)},
$$

where $g(1)$ is given by equation (2). Less homogeneous good is consumed when the product differentation and/or the job heterogeneity increases since both factors increase profit margins and with free entry, also the number of firms. In this case, a larger number of firms increases the resource cost needed to produce the differentiated good, $n(F+K)$, and therefore decreases the amount of residual consumption of the homogeneous good.

\section{Optimum without congestion}

\subsection{The welfare function}

We now compute the first-best optimum. The welfare function can be derived from the indirect utility function (5) in the symmetric case (all subcenters are of equal size). At symmetry, the utility of an individual who works at $i$ and purchases from subcenter $k$ is (see equation (5)): $U_{i k}=\left[\Omega^{o}+(w-p)^{o}\right]+\mu^{w} \varepsilon_{i}+$ $\mu^{d} \varepsilon_{k}$. Note that, at the symmetric optimum, $(p-w)^{o}=c$ so that:

$$
\Omega^{o}=\left(-\alpha^{w} t-\beta\right)+\theta(1-\beta)+h-\alpha^{d} t-\frac{n}{N}(F+S)-T
$$

Recall the government budget equation is $n S+N T=n K$. Then:

$$
\Omega^{o}+(w-p)^{o}=\Psi-\frac{n}{N}(F+K)
$$

where:

$$
\Psi=-\beta+\theta(1-\beta)+h-c^{1}-\left(\alpha^{h}+\alpha^{d}+\alpha^{w}\right) t .
$$


The welfare function is defined as the expected maximum utility: $W(n)=$ $E\left[\max _{i, k} U_{i k}\right]$. This has the property of a welfare function and satisfies Roy's identity (see Anderson, et al. 1992). The first-best optimum in the short run (exogeneous number of subcenters) and in the long run are characterized by:

Proposition 2 In the absence of congestion, the short-run first-best optimum welfare function is given by:

$$
W(n)=\Psi-\frac{n}{N}(F+K)+\left(\mu^{d}+\mu^{w}\right) \log (n),
$$

where $\Psi$ is given by 20. The long-run first-best optimum number of subcenters is

$$
n^{o}=\left(\mu^{d}+\mu^{w}\right) \frac{N}{(F+K)} .
$$

Proof. Using equation (19) and the i.i.d. property, we get

$W(n)=E\left[\max _{i, k} U_{i k}\right]=\Psi-\frac{n}{N}(F+K)+E\left[\max _{i, k}\left(\mu^{w} \varepsilon_{i}\right)\right]+E\left[\max _{i, k}\left(\mu^{d} \varepsilon_{k}\right)\right]$.

Recall that with the double exponential distribution: $E\left[\max _{i} \varepsilon_{i}\right]=\ln (n)$, Then:

$$
W(n)=\Psi-\frac{n}{N}(F+K)+\left(\mu^{d}+\mu^{w}\right) \log (n) .
$$

This function is concave in $n$. The optimal number of subcenters, $n^{o}$ is obtained by differentiation of $W(n)$ where $n$ is treated as a real number.

At the optimum, the consumption of the homogenous good is $g^{o}=g\left(n^{o}\right)$ or

$$
g^{o}=\theta-c^{1}-\left(\alpha^{w}+\alpha^{d}+\alpha^{h}\right) t-\left(\mu^{d}+\mu^{w}\right)=g(0)-\left(\mu^{d}+\mu^{w}\right) .
$$

Where $g(n)$ is given by 2 . Note that this expression is independent of the fixed costs $F$ and $K$. The comparative statics on the first-best number of subcenters and on the consumption of the goods are left to the reader.

\subsection{Equilibrium versus optimum number of subcenters}

We can now compare the equilibrium and the optimum numbers of subcenters. Note that:

$$
(p-w)^{e}=(p-w)^{o}+\left(\mu^{d}+\mu^{w}\right) \frac{n}{n-1},
$$

that is to say firms charge a price (net of wage) above the socially optimal level $(c)$. However the excessive price level will not induce distortions in the 
economy in the short run since the demand for the differentiated goods and the differentiated labour supply are inelastic. We show below that the market power of firms induces excessive entry in the long run.

If firms pay the total cost of the road infrastructure to their subcenter $(S=$ $K)$, the equilibrium number of subcenters is larger than the optimum one $\left(n^{f}>\right.$ $\left.n^{o}\right)$, where $n^{f}$ is given by (18), and $n^{0}$ is given by (22): $n^{f}=1+\left(\mu^{d}+\mu^{w}\right) \frac{N}{F+K}$ and

$$
n^{f}=1+n^{o} .
$$

[8] showed that monopolistic competition in a product market with a logit model always generates an overentry of exactly one firm. We generalised this result to a general equilibrium context. The intuition for this result is that the introduction of an heterogeneous job market corresponds to an additional source of heterogeneity. However, since the labour and product market are related, the total degree of product heterogeneity stays about the same and the number of firms is too large by exactly one unit as in the case where there is only product differentiation.

Assume that $1 \leq n^{o}$, that is $(F+K) / N \leq\left(\mu^{d}+\mu^{w}\right) \cdot{ }^{5}$ In this case, since there is excessive entry, there exists a level of tax which can decentralize the social optimum. The optimal tax is given by:

$$
S=\frac{n^{o} K+F}{\left(n^{o}-1\right)}
$$

Therefore the firm should optimally be charged more than the price of the infrastructures (since $S>K$ ). We have.

Proposition 3 In the absence of congestion, in a free-entry Nash equilibrium, the first-best optimum can be decentralized by a levy per firm larger than the infrastructure cost per subcenter. If the levy covers exactly the infrastructure cost per subcenter, at equilibrium there is one subcenter too many.

\section{Equilibrium with congestion}

\subsection{Model setting}

We have assumed till now that the travel time on road $i, t_{i}$, is constant. From here on we drop this assumption so that the travel time cost on road $i$ is an increasing function of the number of users on this road. Each road is occupied by the shoppers and by the commuters as well as by the trucks that deliver the

\footnotetext{
${ }^{5}$ The minimum number of firm at the optimum is equal to one, since each consumer has to buy a product.
} 
intermediate input from the center to the subcenters. The total usage on road $i$, expressed in car equivalent, is:

$$
\rho_{i}=N\left[\left(\kappa \alpha^{h}+\alpha^{d}\right) P_{i}^{d}+\alpha^{w} P_{i}^{w}\right] .
$$

where $\kappa$ represents the car equivalent of a truck carrying the homogenous good. The $\alpha^{\prime} s$ can also to some extent take into account the difference in timing of the three types of road use.

We assume that the relation between travel cost, $t_{i}$, and total activity on the road $i, \rho_{i}$, is given by:

$$
t_{i}=t+\delta \frac{\rho_{i}}{s}
$$

where $s$ is the capacity of the road measured in car equivalent (for the time period considered in the model), and $\delta$ is a coefficient that translates waiting time and schedule delay costs in equivalent queueing time. The first term represents the transport time in the absence of any congestion. The second term in (26) represents the variable travel cost. This expression is the reduced form of the bottleneck model [4] where road users decide on their trip timing (with no congestion pricing).

Recall the market clearing condition (13): $P_{i}^{d}=P_{i}^{w}$. Equation (26) reduces to:

$$
t_{i}=t+\delta \frac{N}{s} \alpha P_{i}^{d}=t+\delta \frac{N}{s} \alpha P_{i}^{w},
$$

where $\alpha \equiv \kappa \alpha^{h}+\alpha^{d}+\alpha^{w}$. In the symmetric case, $P_{i}^{w}=P_{i}^{d}=1 / n$ and the travel cost, denoted by $t^{e}$, is the same on all routes:

$$
t^{e}=t+\frac{\delta}{n} \frac{N}{s} \alpha
$$

\subsection{Demand for goods and supply of labour}

With congestion, the indirect utility of a consumer working at $i$ and consuming at $k$ is $U_{i k}=\Omega_{i k}+w_{i}-p_{k}+\mu^{w} \varepsilon_{i}+\mu^{d} \varepsilon_{k}$, where:

$$
\Omega_{i k}=\left(-\alpha^{w} t_{k}-\beta\right)+\theta(1-\beta)+h-\alpha_{i}^{d} t_{i}+(1 / N) \sum_{i=1 \ldots n} \pi_{l}-T .
$$

Using the same notation as in the non-congested case, this expression can we written as:

$$
U_{i k}=\Omega-\Lambda^{w} P_{i}^{w}-\Lambda^{d} P_{k}^{d}+w_{i}-p_{k}+\mu^{w} \varepsilon_{i}+\mu^{d} \varepsilon_{k},
$$

where $\Omega$ is given by equation (9), $\Lambda^{w}=\alpha^{w} \delta \frac{N}{s} \alpha$ and $\Lambda^{d}=\alpha^{d} \delta \frac{N}{s} \alpha$. 
As in the no-congestion case, we need to compute the derivative $d g\left(w_{i}\right) / d w_{i}$, where $p_{i}=g_{i}\left(w_{i}\right)$ (see (14) in the non-congestion case). With congestion, the probability that a consumer purchases good $i$ is:

$$
P_{k}^{d}=\frac{\exp \left(\frac{-p_{k}-\Lambda^{d} P_{k}^{d}}{\mu^{d}}\right)}{\sum_{l=1 \ldots n} \exp \left(\frac{-p_{l}-\Lambda^{d} P_{l}^{d}}{\mu^{d}}\right)} .
$$

This equation reduces to (12), when the variable travel time is zero or in the symmetric case $\left(P_{k}^{d}=1 / n\right)$. This is an implicit equation since the travel time on route $k$ depends on the total traffic on route $k$, which is an increasing function of $P_{k}^{d}$ (see equation (27)).

Since the travel costs depend on congestion, they cannot be assumed to be symmetric. Indeed, when a firm deviates from a symmetric candidate equilibrium, it will affect road use and travel costs. For example, a price cut in subcenter $i$ will increase the level of demand, labour supply and intermediate inputs and therefore the level of congestion and the travel cost $t_{i}$.

Using the implicit function theorem, we get:

$$
\frac{d P_{k}^{d}}{d p_{k}}=-\frac{\frac{1}{\mu^{d}} P_{k}^{d}\left(1-P_{k}^{d}\right)}{1+\frac{\Lambda^{d}}{\mu^{d}} P_{i}^{d}\left(1-P_{i}^{d}\right)},
$$

Therefore, in the symmetric case $P_{i}^{d}=1 / n$ :

$$
\left.\frac{d P_{i}^{d}}{d p_{i}}\right|_{S y m}=-\frac{\frac{1}{\mu^{d}} \frac{1}{n}\left(\frac{n-1}{n}\right)}{1+\frac{\Lambda^{d}}{\mu^{d}} \frac{1}{n}\left(\frac{n-1}{n}\right)}<0 .
$$

Note that the price sensitivity in the symmetric case decreases as the impact of congestion measured by $\Lambda^{d}$ (that contains $\alpha^{d}$ and $\alpha$ ) gets larger. Congestion decreases the incentive to cut prices, since a lower price implies more customers, more workers and more intermediate deliveries and therefore more congestion, which both reduce the benefit of the initial price cut. In fact the initial price cut is compensated partially by congestion so that the firm is exchanging a lower profit margin for more time losses rather than for more customers. With an extremely high level of congestion $\left(\Lambda^{d} \rightarrow \infty\right)$ the demand for one specific variety is inelastic.

Similarly, for the labour market we have:

$$
P_{i}^{w}=\frac{\exp \left(\frac{w_{i}-\Lambda^{w} P_{i}^{w}}{\mu^{w}}\right)}{\sum_{j=1 \ldots n} \exp \left(\frac{w_{j}-\Lambda^{w} P_{j}^{w}}{\mu^{w}}\right)}>0 .
$$

This expression reduces to (11) when the variable travel time is zero: when there is no congestion. At a symmetric situation: 


$$
\left.\frac{d P_{i}^{w}}{d w_{i}}\right|_{S y m}=\frac{\frac{1}{\mu^{w}} \frac{1}{n}\left(\frac{n-1}{n}\right)}{1+\frac{\Lambda^{w}}{\mu^{w}} \frac{1}{n}\left(\frac{n-1}{n}\right)}
$$

The market clearing condition $P_{i}^{w}-P_{i}^{d}=0$ (see (13)) has a unique solution $p_{i}=g_{i}\left(w_{i}\right)$ given that $d P_{i}^{w} / d w_{i}>0$ and $d P_{i}^{d} / d p_{i}<0$. We have:

$$
\left.\frac{d p_{i}\left(w_{i}\right)}{d w_{i}}\right|_{S y m}=-\frac{\mu^{d}}{\mu^{w}} \frac{1+\frac{\Lambda^{d}}{\mu^{d}} \frac{1}{n}\left(\frac{n-1}{n}\right)}{1+\frac{\Lambda^{w}}{\mu^{w}} \frac{1}{n}\left(\frac{n-1}{n}\right)} .
$$

There are two limiting cases of interest. First, without congestion, this expression reduces to equation (14). This case can also be obtained in the limit where the product and the labour market diversities are very large compared to congestion $\left(\mu^{d}>>\Lambda^{d}\right.$ and $\left.\mu^{w}>>\Lambda^{w}\right)$. Second, when congestion costs are present and very high compared to the product and labour market diversities $\left(\Lambda^{d}>>\mu^{d}\right.$ and $\left.\Lambda^{w}>>\mu^{w}\right)$, then:

$$
\left.\frac{d p_{i}}{d w_{i}}\right|_{S y m}=-\frac{\Lambda^{d}}{\Lambda^{w}}-\frac{\alpha^{d}}{\alpha^{w}} .
$$

In this case the wages and the prices are solely driven by the level of congestion, since the workers and the shoppers select their destination only as a function of variable travel times.

\subsection{Short run equilibrium}

We study first the equilibria in the absence of government interventions: no congestion pricing, no limit on the number of centers and an exogenous road capacity.

We know that the marginal cost is $c_{i}=c^{1}+\alpha^{h} t_{i}$, where $t_{i}=t+\delta \frac{\rho_{i}}{s}$, and road usage $\rho_{i}$ is given by (25). Since the travel time $t_{i}$ is variable, the marginal cost becomes variable and endogenous. We have

$$
c_{i}=c^{1}+\alpha^{h}\left(t+\delta \frac{\rho_{i}}{s}\right)=c+\Lambda^{h} P_{i}^{w},
$$

where $\Lambda^{h}=\alpha^{h} \delta \frac{N}{s} \alpha$ (using equation (27)), and where we have defined $c=$ $c^{1}+\alpha^{h} t$. This means that the firm bears directly, via the intermediate delivery cost, part of the congestion costs it creates. Using the market clearing condition, the profit of Firm $i$ is

$$
\left.\widetilde{\pi}_{i}\left(w_{i}, w_{-i}, p\right)=\left[g_{i}\left(w_{i}\right)-w_{i}-c-\Lambda^{h} P_{i}^{w}\right)\right] N P_{i}^{w}-(F+S) .
$$

The first-order condition for optimal wage (and price) setting is: $d \widetilde{\pi}_{i} / d w_{i}=0$ or 


$$
\left[\frac{d g_{i}\left(w_{i}\right)}{d w_{i}}-1\right] P_{i}^{w}+\left[g_{i}\left(w_{i}\right)-w_{i}-c-2 \Lambda^{h} P_{i}^{w}\right] \frac{d P_{i}^{w}}{d w_{i}}=0
$$

Substituting the expressions (34) and (33), the first-order condition, at the symmetric candidate equilibrium reduces to:

$$
\begin{gathered}
{\left[\frac{\mu^{d}}{\mu^{w}}\left(1+\frac{\Lambda^{d}}{\mu^{d}} \frac{1}{n}\left(\frac{n-1}{n}\right)\right)+1+\frac{\Lambda^{w}}{\mu^{w}} \frac{1}{n}\left(\frac{n-1}{n}\right)\right]} \\
\quad-\left(p^{e}-w^{e}-c-\Lambda^{h} \frac{2}{n}\right) \frac{1}{\mu^{w}} \frac{n-1}{n}=0 .
\end{gathered}
$$

Therefore, the candidate equilibrium price is given by the solution of (36):

$$
p^{e}=c+\frac{\Lambda^{h}}{n}+w^{e}+\left(\mu^{d}+\mu^{w}\right) \frac{n}{n-1}+\frac{\delta}{n} \frac{N}{s} \widehat{\alpha}^{2}, .
$$

where $\widehat{\alpha}=\sqrt{\alpha\left(\alpha^{h}+\alpha^{d}+a^{w}\right)^{6}}$ and where $\Lambda^{h}=\alpha^{h} \delta \frac{N}{s} \alpha$.

Proposition 4 With congestion but without congestion pricing, there exists a unique symmetric Nash equilibrium in prices and wages given by:

$$
p^{e}=c+\frac{\Lambda^{h}}{n}+w^{e}+\left(\mu^{d}+\mu^{w}\right) \frac{n}{n-1}+\frac{\delta}{n} \frac{N}{s} \widehat{\alpha}^{2}
$$

Proof. See Appendix C.

Note that without congestion, the equilibrium price reduces to equation (17). With congestion, there are two additional positive terms in the RHS. First the marginal production cost is now $c+\Lambda^{h} / n+w^{e}$ and contains a congestion term translating the increased cost of intermediate deliveries. The second term is related to the congestion created by shopping, commuting and intermediate delivery traffic and represents the increased market power effect.

The markup $\left(p^{e}-c-\Lambda^{h} / n-w^{e}\right)$ now has two components. The first one is the product/wage heterogeneity term (proportional to $\left(\mu^{d}+\mu^{w}\right)$ ), as in the non-congested case. The second term, represents the externality due to congestion $^{7}$ As discussed, congestion reduces the incentive to cut prices, and therefore, increases equilibrium prices. This may explain why shops often lobby against policy measures which aim to improve traffic conditions in general although a firm individually will be in favour of local improvements of traffic, i.e. measures which improve the accessability to.workers and consumers.

The short run equilibrium profit (see 35 and 37 is:

$$
\pi^{e}(s)=\left(\mu^{d}+\mu^{w}\right) \frac{N}{(n-1)}+\frac{\delta}{s}\left(\frac{\widehat{\alpha} N}{n}\right)^{2}-(F+S)
$$

which is an increasing function of the congestion level.

\footnotetext{
${ }^{6}$ Note than when $\kappa=1, \widehat{\alpha}=\alpha$.

${ }^{7}$ The total cost is $T C=\alpha N t^{e}=\alpha N\left(t+\delta \alpha \frac{N}{s n}\right)$. Therefore the externality, which is the difference between the marginal cost and the average cost is equal to: $\delta \alpha^{2} \frac{N}{s n}=\alpha\left(t^{e}-t\right)$.
} 


\subsection{Long run equilibria}

For a fixed level of road capacity $s$, the free entry equilibrium with congestion denoted by $n^{f}(s)$ solves $\pi^{e}=0$. In order to study the free entry equilibrium, we need to specify the fixed levy per firm $\mathrm{S}$. As the default value, we use $S=K$. This leads to a cubic equation, and its solution is not too illuminating. The profit $\pi^{e}(s)$ is a decreasing function of the number of subcenters $n$. Given that the equilibrium profit with congestion is larger than without, the free entry equilibrium with congestion involves more firms than without congestion: $n^{f}(s)>n^{f}$.

We can find a lower bound $\left(n^{o}(s)<n^{f}(s)\right)$ and an upper bound for the solution of (38). As lower bound, we use $n^{o}(s)$ that is the solution of the following equation:

$$
\left(\mu^{d}+\mu^{w}\right) \frac{N}{n^{o}(s)}+\frac{\delta}{s}\left(\frac{\widehat{\alpha} N}{n^{o}(s)}\right)^{2}-(F+K)=0
$$

We will show in the next section that $n^{o}(s)$ is the optimal number of firms for given road capacity and in the absence of congestion charging. Observe that $\pi^{e}\left(n^{o}\right)>0, n^{o}(s)<n^{f}(s)$. So that equation 39 has a unique positive root:

$$
n^{o}(s)=n^{o}+\frac{n^{o}}{2}\left(\sqrt{\left(\frac{\widehat{\alpha} N}{n^{o}}\right)^{2} \frac{4 \delta}{s(F+S)}+1}-1\right)
$$

where $n^{o}=\left(\mu^{d}+\mu^{w}\right) N /(F+S)$, represents the optimum number of subcenters without congestion (see equation (22)) provided that the firm pays the road infrastructure cost $(S=K)$.

As upper bound for $n^{f}(s)$, we use $n^{o}(s)+1$. We have:

$$
\pi^{e}\left(n^{o}(s)+1\right)=\left(\mu^{d}+\mu^{w}\right) \frac{N}{n^{o}(s)}+\frac{\delta}{s}\left(\frac{\widehat{\alpha} N}{n^{o}(s)+1}\right)^{2}-(F+K) .
$$

Subtracting (39) from this equation, we get:

$$
\pi^{e}\left(n^{o}+1\right)=\frac{\delta}{s}(\widehat{\alpha} N)^{2}\left(\frac{1}{\left(n^{o}+1\right)^{2}}-\frac{1}{\left(n^{o}\right)^{2}}\right)<0 .
$$

As a consequence, $n^{f}(s)<n^{o}(s)+1$.

Summarizing, for given road capacity, in the absence of road pricing and for an infrastructure charge on firms $S=K$, we have an upper and lower bound for the equilibrium number of subcenters where $n^{o}(s)$ denotes the optimal number of subcenters. 


$$
n^{o}(s)<n^{f}(s)<n^{o}(s)+1 ; n^{f}<n^{f}(s)
$$

Therefore, the equilibrium number and the optimum number of subcenters increases with congestion.

\section{Optimum with congestion}

\subsection{Optimum number of subcenters with fixed road ca- pacity and no congestion charging}

The policy maker has three types of instruments available to improve the Nash equilibrium. He can influence the number of subcenters, he can optimise the road capacity and he can implement congestion charging. The three instruments are to some extent substitutes and it may be necessary to use them all to achieve the first best. We first analyse the gains we can achieve by regulating only the number of subcenters. Next we add to this first instrument the optimisation of road capacity. In a final section we discuss the use of congestion charging.

We have the same expression for the welfare function as in the case without congestion (see equation (21). However, now the transportation costs are no longer constant since they depend on the number of cars (and trucks) on the roads and on the road capacities. Using the definition of transport costs, we rewrite equation (21) in a way that separates the variable transport costs from the other costs:

$$
W(n, s)=\Psi-\frac{n}{N}(F+K)+\left(\mu^{d}+\mu^{w}\right) \log (n)-(\widehat{\alpha})^{2} \frac{\delta}{n} \frac{N}{s},
$$

where $\Psi$ is given by(20)). We first consider the long-run equilibrium assuming that the size of each road is determined administratively and not optimised (for example, each road has two lanes inbound and two lanes outbound).

For the first-best optimal number of subcenters, we consider the first-order condition $d W(n, s) / d n=0$. It leads to a unique maximum $n^{o}(s)$ which solves:

$$
\left(\mu^{d}+\mu^{w}\right) \frac{N}{n^{o}(s)}+\frac{\delta}{s}\left(\frac{\widehat{\alpha} N}{n^{o}(s)}\right)^{2}-(F+K)=0 .
$$

This is the same equation as (39). As a consequence, the optimal number of subcenters corresponds to the lower bound proposed for the equilibrium number of subcenters, so that there is excess entry: $n^{o}(s)<n^{f}(s)$. The optimal number of subcenters increases with the level of congestion and $n^{o}<n^{o}(s)$ where $n^{o}$ is the optimal number of subcenters in the absence of congestion. Note also that $\frac{d n^{f}(s)}{d s}<0$.

Proposition 5 shows that, at the long run free entry equilibrium and at the optimum, congestion induces more (and smaller) subcenters. Excessive entry remains the norm but overentry still occurs and there is at most one subcenter too many. 
Proposition 5 Assume fixed road capacity and no congestion charging. In the long run, congestion increases the equilibrium and the optimal number of subcenters. If the fixed levy on firms exactly covers the infrastructure cost per subcenter, the equilibrium number of firms is never smaller than the optimal number of firms and there is at most one subcenter too many. ${ }^{8}$

\subsection{Optimum number of subcenters and optimum road capacities without road pricing}

Assume now that the government can also determine the size of the roads. We assume a linear construction technology. In this case, we can solve for the optimum capacity, for a fixed number of subcenters.

$$
W(n, s)=\Psi-\frac{n}{N}\left(F+\xi^{2} s\right)+\left(\mu^{d}+\mu^{w}\right) \log (n)-(\widehat{\alpha})^{2} \frac{\delta}{n} \frac{N}{s},
$$

where the infrastructure cost is $K=\xi^{2} s$, where $\xi^{2}$ represents the unit infrastructure cost..$^{9}$ Higher transport capacity has two impacts in the economy. First, it decreases the transportation cost (since there is congestion) and second it takes away resources.

For $n$ fixed, the optimal capacity solves: $\partial W(n, s) / \partial s=0$, and this leads to:

$$
s^{o}(n)=\frac{\widehat{\alpha} N}{n \xi} \sqrt{\delta} .
$$

In the optimum, the total construction cost per individual is independent of the number of subcenters and is equal to:

$$
C C=\frac{n}{N} \xi^{2} s^{o}(n)=\widehat{\alpha} \xi \sqrt{\delta} .
$$

The congestion cost for optimised capacity is $\widehat{\alpha} \xi \sqrt{\delta}$; and therefore equal to the construction cost per individual.

Proposition 6 When road capacities are optimally chosen, the construction technology is linear and when there is no congestion charging, the average congestion cost per individual is equal to the construction cost per individual $\xi \sqrt{\delta}$. The total construction cost is independent of the number of subcenters.

We then have for the welfare level:

$$
\widehat{W}(n)=W\left[n, s^{o}(n)\right]=\Psi-\frac{n F}{N}+\left(\mu^{d}+\mu^{w}\right) \log (n)-2 \widehat{\alpha} \xi \sqrt{\delta} .
$$

\footnotetext{
${ }^{8}$ Of course, as in the non-congested case, there exist an optimal level of tax $S$ which decentralizes the social optimum.

${ }^{9}$ Basically this amount to assume that the cost to construct two lanes is twice the cost of constructing one lane. In a more refined version of the model the cost would be concave.
} 
The optimum number of subcenters in the absence of road pricing but with optimal road capacity $\widehat{n}^{o}$ solves: $d \widehat{W}(n) / d n=0$ or

$$
\widehat{n}^{o}=\left(\mu^{d}+\mu^{w}\right) \frac{N}{F} .
$$

Note that, as a consequence $n^{o}<\widehat{n}^{o}$, where $n^{o}$ is given by 22 .In the long run and when the roads are optimised, the number of subcenters is larger with than without congestion. Without congestion, the incentive to have more sub-centers is to benefit from more product and more labour variety. With congestion, there is an additional incentive to deconcentrate shopping and working place, since more centers tend to decrease overall congestion levels. As extending road capacity is costly, it remains optimal to have more subcenters in the case of optimal road capacity. Note that if the government could decide the number of subcenters given that firms will compete (in the goods and in the labour market), it will again choose $\widehat{n}$. In this case, the welfare level will be the same as in the case where the firms are managed by a central authority subject to the constraint that they have to break even.

\subsection{Optimum number of subcenters and road capacities in the presence of congestion charging}

Before discussing the effect of charging instruments it is useful to remember that we model congestion by using the bottleneck model. In the bottleneck model the different road users reach an equilibrium distribution of their trips over time when the sum of queueing and schedule delay costs are equal. When there is no congestion charging, there is queueing and this is a pure inefficiency as a perfect rearranging of users over time can eliminate all queueing costs.

We will discuss two congestion charging instruments. The first type of toll is a fine toll that can be perfectly differentiated over the full period considered. The second type of instrument is a one step toll. A one step toll means that the relevant period can be subdivided into two periods: one period with a fixed toll and one period without a toll. This is a much simpler but also a socially less performant instrument than a fine toll. We could consider other charging instruments (cordon tolls or parking levies that are not time differentiated) but these can in our simple model be reduced to head taxes per consumer or to a levy per firm. Fixed levies are not able to change the distribution over time of trips and are therefore not efficient in reducing congestion. They can only affect the total level of demand for the differentiated good but this is fixed.

With the bottleneck congestion model [4], the total variable travel cost per individual $(\widehat{\alpha})^{2} \frac{\delta}{n} \frac{N}{s}$ can be reduced by a factor 2 when an optimal fine toll is used and by a factor $4 / 3$ when an optimal one step toll is used. With an optimal fine toll, there are only schedule delay costs left as queueing is by definition inefficient and therefore eliminated. The average congestion charge that corresponds to the fine toll equilibrium will be equal to the average schedule delay cost. With an optimal coarse toll, queueing is not completely eliminated. 
Introducing congestion pricing via a fine toll, will affect the mark-ups in two ways. First via the cost of intermediate deliveries and second via the margin on consumers as this depends on congestion too. The trucks delivering intermediate goods to firms will now pay, on average, a congestion charge but they will on average also experience less congestion. The net effect is zero in the case of the fine toll, so optimal congestion charges do not affect the cost to the firm of intermediate deliveries. The second effect is clearly negative: congestion pricing decreases the mark-up of firms since the congestion protection of the market is largely eliminated: where as decreasing the price attracts new customers and thus more congestion but this congestion is taken care of by the fine toll. Alltogether, the profit margins are smaller with fine tolls than without tolling. Using the same arguments as for Proposition 4, we have:

Proposition 7 Assuming fixed road capacity and optimal congestion pricing, there exists a unique symmetric Nash equilibrium in prices and wages where the producer price and wage is given by:

$$
p_{c p}^{e}=c+\frac{\Lambda^{h}}{n}+w_{c p}^{e}+\left(\mu^{d}+\mu^{w}\right) \frac{n}{n-1}+\frac{\delta}{2 n} \frac{N}{s} \widehat{\alpha}^{2}
$$

and the average consumer price including toll is:

$$
p_{c p}^{e}+\alpha^{d} \frac{\delta}{2 n} \frac{N}{s} \alpha
$$

while the average net wage after deduction of the toll is:

$$
w_{c p}^{e}-\alpha^{w} \frac{\delta}{2 n} \frac{N}{s} \alpha
$$

In this analysis, it is assumed that the firms anticipate the change in the toll level when they decide to change their price. This rational behavior may be questioned. Alternatively, one can assume that the toll level is not changed in reaction to price changes.

Proposition 7 implies that, for any given road capacity and any given number of firms, profit margins will be lower with road pricing. As a consequence the number of subcenters that will exist in the long run will be lower with road pricing than without road pricing.

Assume the government can also determine the size of the roads and price them optimally. Maximising welfare with respect to road capacity s, taking into account that travel costs are reduced by a factor 2 with an optimal fine toll, we obtain:

$$
s_{c p}^{o}(n)=\frac{\widehat{\alpha} N}{n \xi} \sqrt{\frac{\delta}{2}} .
$$

So that in the optimum, the total construction cost per individual is independent of the number of subcenters and is equal to: 


$$
C C_{c p}=\frac{n}{N} \xi^{2} s_{c p}^{o}(n)=\widehat{\alpha} \xi \sqrt{\frac{\delta}{2}} .
$$

Therefore the self-financing result of Proposition 6 holds also with optimal road pricing. Road pricing reduces the total construction costs by a factor $\sqrt{2}$ compared to the no toll equilibrium.

\section{Summary and a numerical illustration}

We start by summarising the results obtained so far. Because the total demand for the differentiated good is fixed, only two parameters matter for the welfare analysis: the number of firms and the total transport costs. The total number of firms depends on the profit margin of the firms in the Nash equilibrium. When there is no congestion, in the equilibrium there is always one subcenter too many (see first line in Table 1). The equilibrium and optimum numbers of subcenters are always (increasing) linear functions of the same parameters $A$ and $\bar{A}: A=$ $\left(\mu^{d}+\mu^{w}\right) N(F+K) /$ and $\left.\bar{A}=\left(\mu^{d}+\mu^{w}\right) N / F\right)$. More heterogeneity (on the product or labour market) leads to a higher optimal number of subcenters. Higher fixed production costs, lead to a lower optimum number of subcenters. When the road size cannot be optimized, the public infrastructure cost also points to a lower optimal number of subcenters.

When capacity is not infinite and congestion may occur, we need to distinguish the case with or without road capacity optimisation and with or without optimal road tolling. We discuss first the case with given road capacity (columns 1 and 2 in Table 1). Without tolling and given road capacity, the short-run profit margin is always larger in the presence of congestion so that the free-entry equilibrium always entails more subcenters than in the situation without congestion (see second line in Table 1). The free entry equilibrium with congestion has at most one subcenter too many. Optimum congestion pricing can reduce but not eliminate the additional profit margins due to congestion. This explains that in equilibrium and with road capacity given, the equilibrium number of firms is highest if there is no congestion pricing (see first column in Table 1).

Any number of subcenters can be implemented by choosing the right fixed levy per firm. For the free-entry equilibrium computed in Table 1, we have assumed that the fixed levy equals the infrastructure costs per firm (firms are then responsable for the construction of the infrastructure). As can be seen in Table 1, we need a fixed levy per firm higher than the infrastructure costs to obtain the optimum number of subcenters. When the planner can optimally choose the road capacity, she compares the welfare cost of congestion with the marginal cost of capacity expansion. Without congestion tolling, the benefit of road expansion will be larger than with road pricing. Indeed, in the case of fine tolls, the optimum road capacity will be smaller by a factor $1 / \sqrt{2}$.

TABLE 1: Long-Run optimum and equilibrium number of firms in the symmetric case under different congestion and policy assumptions 


$\begin{array}{cccc} & \text { Capacity given } & \text { Capacity given } & \text { Optimum capacity } \\ \text { No cong. } & \text { LR equilibrium } & \text { LR optimum } & \text { LR optimum } \\ \text { no toll } & n^{f}=1+A & n^{o}=A & n^{o}=A \\ \text { Cong. } & n^{f}<n^{f}(s) & & n^{o}=\bar{A} \\ \text { no toll } & n(s) \leq n^{f}(s) & n^{o}<n(s) & s(n)=\frac{\widehat{\alpha} N}{n \xi} \sqrt{\delta} \\ \text { Cong. } & n^{f}(s) \leq n^{o}(s)+1 & & n=A^{\prime} \\ \text { fine toll } & n_{c p}^{f}(s)<n^{f}(s) & n_{c p}^{o}<n_{c p}(s) & s(n)=\frac{\widehat{\alpha} N}{n \xi} \sqrt{\delta} \\ & & n_{c p}(s)<n(s) & \end{array}$

with

$$
\begin{aligned}
A & =\left(\mu^{d}+\mu^{w}\right) \frac{N}{F+K} \\
. \bar{A} & =\left(\mu^{d}+\mu^{w}\right) \frac{N}{F}
\end{aligned}
$$

The symmetric equilibria can be illustrated numerically with a simple example. Consider a city center with 1 million inhabitants who all work $8 \mathrm{~h}$ a day, consume one unit of the differentiated good per day and work one hour per day for the production of the differentiated good.

The price of non-differentiated labour is set to one and taken as numéraire. The individuals make one shopping and one commuting trip every 10 days to one of the subcenters that produces and sell the differentiated good. We assume also that one standard truck delivers enough intermediate goods to produce 50 units of the differentiated good and that one truck has the same congestion effect as 2 cars. By assumption, the fixed set-up cost per firm equals 75000 units and a subcentre also requires a fixed public input of 75000 units. One unit of the differentiated good requires an intermediate input that can be produced using 0.1 units of homogenous labour. ${ }^{10}$

All individuals spend half an hour in transportation per day if there is no congestion (note that this includes the cost of renting the car). When there is congestion we assume that, without tolls residents' transport costs increase by $50 \%$ in the free entry equilibrium (without tolls, taxes and capacity expansion). For $\delta$, the time cost parameter in the bottleneck model, we use the estimate of [4] and choose a value of 0.2425 - this is to be understood as a travel time cost and means that queueing and schedule delay costs are $24 \%$ of the wage. We assume that the traffic is evenly distributed over three identical time periods (morning peak, lunch peak and evening peak). Finally, we assume in the base case that $\mu^{d}$ and $\mu^{w}$ both equal 0.2 . Table 2 illustrates for these base case values the number of subcenters (1) when there is no congestion, (2) when there is congestion but no tolls, and (3) when there is congestion but first-best

\footnotetext{
${ }^{10}$ This means that each inhabitant works about half an hour per day in order to produce and maintain the roads, the infrastructure in the subcenters and the production equipment.
} 
congestion pricing. In this table, we report results as real numbers (even if the number of firms can also be treated as integer). In the absence of congestion, we have 3.7 subcenters in the free entry equilibrium. We report the gross margin $p-w$ and not $p$ and $w$ separatly since $w$ can be chosen freely. This margin will be higher when the benefits of variety (for products and for workplaces) gets larger. If there is no congestion, the optimal number of subcenters equals the free entry equilibrium number minus one (2.7) and the welfare loss per individual due to the excessive number of subcentres is small: it equals 0.023 to be compared with an expenditure on differentiated goods of 1.62 and a total welfare level of 10.565. With congestion, we see that the gross margin increases and the free entry number of firms increases from 3.7 to 5.014. The introduction of congestion results in a lower welfare level: $(-0.330)$. One can use three policies to improve the free entry equilibrium with congestion. The first is to limit the number of subcenters. Using fixed fees on firms that exceed the public infrastructure costs, this policy would result in a lower number of firms: 4.35 rather than 5.014. The welfare gain of this type of policy is also very small: 0.004. A second policy that can be used is to combine a different number of firms and a different road size (by appropriate taxes). The optimal policy would, in this case, result in slightly more subcenters (5.333) but smaller roads. (94\% of the road size in the free entry equilibrium). Recall that the road size in the free entry equilibrium with congestion was by assumption optimal for this equilibrium number of firms. The welfare gain of being able to adjust the number of subcenters becomes much larger when the road size can also be adjusted: the welfare gain compared to the free entry equilibrium is 0.124 . A third policy, that can be used is to introduce road pricing. This will again decrease the number of subcenters: in the free entry equilibrium only 4.407 firms can survive leading to a welfare gain of 0.149 . We can combine the three policies in different ways. When we add to road pricing, the possibility of controlling the number of subcenters, we have a smaller number of subcenters: 3.78 and this means a slightly higher welfare gain than road pricing only: 0157 instead of 0.149 . When we add on top of these two policies the optimisation of the road size, it is again optimal to have a larger number of subcenters (5.333) and the optimal road size is now only $67 \%$ of what is was in the free entry equilibrium. Combining the three policies generates the highest welfare gain: 0.272 .

\section{INSERT TABLE 2 about here}

Many sensitivity studies are possible. We chose to increase the benefit of variety parameters $\mu^{d}$ and $\mu^{w}$ from 0.2 to 0.6 . Table 3 reports all the results for this case. We see in the equilibria a much higher number of firms (9 rather than 3.7 in the absence of congestion) and a much smaller increase in the equilibrium number of firms when we introduce congestion (again calibrated such as to add $50 \%$ to the travel time). The number of firms increases from 9 to 10.523 (a $17 \%$ increase) while for the smaller $\mu$ values reported in the base case, the equilibrium number of firms increases by $77 \%$ when we introduced congestion. The 
reason is that the influence of congestion on the profit margins becomes much smaller compared to the benefit of variety. The relative contribution of the three policy instruments is different than in the base case. The control of the number of subcenters is an ineffective policy instrument with very small welfare gains: ranging from 0.004 in the case with congestion to 0.009 in the case without congestion. The introduction of road pricing again generates an important welfare gain: 0.140 . In this case, the most important policy instrument is the control of the size of the roads combined with the control of the number of subcenters. This policy that induces many more subcenters (16 rather than 10) and much narrower roads ( $46.5 \%$ of the base case) leads to the most efficient equilibrium.

We have studied so far the symmetric model which allows us to derive analytical results. It is straightforward to write down the non-symmetrical version where costs, quality and transport costs are different for the different subcenters. In this case it is necessary to use numerical approaches based on variational inequalities to analyse the properties of the solutions.

\section{INSERT TABLE 3 about here}

\section{References}

[1] Anas, A., Arnott R and Small K., (1998), "Urban spatial structure", Journal of Economic Literature, September, p 1426-1464.

[2] Anderson, S., A. de Palma and Y. Nesterov, (1995), "Oligopolistic competition and the optimal provision of products", Econometrica 63, , p 1281-1301.

[3] Ginsburgh V. and M. Keyzer, (1997), "The structure of applied general equilibrium models", MIT Press, Cambridge, 1997.

[4] Arnott R., A. de Palma and R. Lindsey, "A structural model of peak period congestion: a traffic bottleneck model with elastic demand", American Economic Review, 1993, 83(1), p 161-179.

[5] Fujita M. and J.-F. Thisse,"Economics of Agglomeration", Cambridge University Press, Cambridge 2002.

[6] Van Dender K., "Nash-Bertrand Competition in a duopoly with congestion", Discussion Paper, Irvine.

[7] Edelson N. M. "Congestion tolls under monopoly", American Economic Review, 1971, p 873-882.

[8] Anderson S., A. de Palma and J.-F. Thisse, "Discrete Choice Theory of Product Differentiation", MIT Press, Cambridge, 1992. 
[9] Anderson, S. and A. de Palma (2001), "Product diversity in asymmetric oligopoly: is the quality of consumer goods too low?", The Journal of Industrial Economics, Vol XLIX, p 113-135. 


\begin{tabular}{|l|l|l|l|}
\hline \multicolumn{4}{|c|}{ Free-entry equilibrium: $\mathrm{n}^{\mathrm{e}}$} \\
\hline & No congestion & Unpriced congestion & $\begin{array}{l}\text { Congestion \& fine } \\
\text { toll }\end{array}$ \\
\hline $\mathrm{n}^{\mathrm{e}}$ & 3.7 & 5.014 & 4.407 \\
\hline $\mathrm{p}^{\mathrm{e}}-\mathrm{w}^{\mathrm{e}}$ & 0.54 & 0.66 & 0.65 \\
\hline Welfare $[\mathrm{hr}]$ & 10.565 & 10.235 (reference) & 10.384 (reference) \\
\hline $\mathrm{s}$ (index) 26,309 & $\infty$ & 100 & 100 \\
\hline \multicolumn{4}{|l|}{ Optimized number of subcenters: $\mathrm{n}^{\circ}(\mathrm{s}) ; \mathrm{s}=100$} \\
\hline $\mathrm{n}^{\circ}(\mathrm{s})$ & 2.7 & 4.35 & 3.78 \\
\hline Welfare gain & 0.023 & 0.004 & 0.008 \\
\hline \multicolumn{4}{|l|}{ Optimized number of subcenters $\mathbf{n}^{\circ}$ and optimized road size $\mathrm{s}^{\circ}$} \\
\hline $\mathrm{s}^{\circ}$ (index) & 94 & 67 \\
\hline $\mathrm{n}^{\circ}$ & 5.333 & 5.333 \\
\hline $\begin{array}{l}\text { Welfare gain wrt } \\
\text { "reference" }\end{array}$ & 0.124 & 0.123 \\
\hline
\end{tabular}

Table 2 Numerical illustration for the Base case parameters: $\mu^{\mathrm{w}}=\mu^{\mathrm{d}}=0.2$.

\begin{tabular}{|l|l|l|l|}
\hline \multicolumn{5}{|c|}{ Free-entry equilibrium: $\mathrm{n}^{\mathrm{e}}$} \\
\hline & No congestion & Unpriced congestion & $\begin{array}{l}\text { Congestion \& fine } \\
\text { toll }\end{array}$ \\
\hline $\mathrm{n}^{\mathrm{e}}$ & 9 & 10.523 & 9.811 \\
\hline $\mathrm{p}^{\mathrm{e}}-\mathrm{w}^{\mathrm{e}}$ & 1.33 & 1.46 & 1.45 \\
\hline Welfare [hr] & 11.882 & 11.588 (reference) & 11.728 (reference) \\
\hline $\mathrm{s}$ (index) 12,536 & $\infty$ & 100 & 100 \\
\hline \multicolumn{4}{|l|}{ Optimized number of subcenters: $\mathrm{n}^{\circ}(\mathrm{s}) ; \mathrm{s}=100$} \\
\hline $\mathrm{n}^{\circ}(\mathrm{s})$ & 8 & 9.83 & 8.99 \\
\hline Welfare gain & 0.009 & 0.004 & $\sim 0$ \\
\hline \multicolumn{4}{|l|}{ Optimized number of subcenters $\mathbf{n}^{\circ}$ and optimized road size $\mathbf{s}^{\circ}$} \\
\hline $\mathrm{s}^{\circ}$ (index) & 66 & 47 \\
\hline $\mathrm{n}^{\circ}$ & \multicolumn{4}{|c|}{16} & 16 \\
\hline $\begin{array}{l}\text { Welfare gain wrt } \\
\text { "reference" }\end{array}$ & \multicolumn{4}{|c|}{0.629} \\
\hline
\end{tabular}

Table 3 Numerical illustration for the Base case parameters: $\mu^{\mathrm{w}}=\mu^{\mathrm{d}}=0.6$. 


\section{APPENDIXES}

\section{A Proof of Proposition 1}

It suffices to show that the profit function is quasi-concave. Since there exists a candidate equilibrium, quasi-concavity is sufficient to guarantee that this candidate equilibrium is Nash. We prove below that at any extremum, the function is concave.

At any extremum, the first-order condition is satisfied:

$$
\frac{1}{N} \frac{d \tilde{\pi}_{i}}{d w_{i}}=\left[-\left(\frac{\mu^{d}}{\mu^{w}}+1\right)+\left(f_{i}\left(w_{i}\right)-w_{i}-c\right) \frac{\left(1-P_{i}^{w}\right)}{\mu^{w}}\right] P_{i}^{w} .
$$

The corresponding second-order condition is:

$$
\frac{1}{N}{\frac{\mu^{w}}{P_{i}^{w}\left(1-P_{i}^{w}\right)}}_{\frac{d^{2} \tilde{\pi}_{i}}{d w_{i}^{2}}}^{\left.\right|_{\frac{d \tilde{\pi}_{i}}{d w_{i}}=0}}=-2\left(\frac{\mu^{d}}{\mu^{w}}+1\right)+\left(f_{i}\left(w_{i}\right)-w_{i}-c\right)\left(1-2 P_{i}^{w}\right) \frac{1}{\mu^{w}}
$$

But, using the fist order condition, we get:

$$
\begin{aligned}
\frac{1}{N} \frac{\mu^{w}}{P_{i}^{w}\left(1-P_{i}^{w}\right)} \frac{d^{2} \widetilde{\pi}_{i}}{\left.d w_{i}^{2}\right|_{\frac{d \tilde{\pi}_{i}}{d w_{i}}=0}} & =-2\left(\frac{\mu^{d}}{\mu^{w}}+1\right)+\frac{\left(\frac{\mu^{d}}{\mu^{w}}+1\right)}{\left(1-P_{i}^{w}\right)}\left(1-2 P_{i}^{w}\right) \\
& =\left(\frac{\mu^{d}}{\mu^{w}}+1\right)\left(-2+\frac{\left(1-2 P_{i}^{w}\right)}{\left(1-P_{i}^{w}\right)}\right),
\end{aligned}
$$

or

$$
\frac{1}{N} \frac{\mu^{w}}{P_{i}^{w}}{\frac{d^{2} \tilde{\pi}_{i}}{d w_{i}^{2}}}_{\mid \frac{d \tilde{\pi}_{i}}{d w_{i}}=0}=-\left(\frac{\mu^{d}}{\mu^{w}}+1\right)<0
$$

Therefore, any turning point, where $d \widetilde{\pi}_{i} / d w_{i}=0$ is such that it is a maximum. As a consequence, the profit function is quasi-concave, and the symmetric candidate equilibrium is a Nash Equilibrium. Q.E.D.

\section{B I.I.D. preferences}

\section{B.1 Computation of the candidate price equilibrium}

- Labour market choices

The choice probabilities of subcenter $i$ is given as before by:

$$
P_{i}^{w}=\operatorname{Pr} o b\left\{w_{i}+\mu^{w} \gamma_{i} \geq w_{j}+\mu^{w} \gamma_{j}, j=1 \ldots n\right\} .
$$


We assume that the random variable $\gamma$ are i.i.d., with cdf (strictly increasing and absolutely continuous) denoted by $G($.$) and density denote by g$ defined on $\mathbb{R}$. We get:

$$
P_{i}^{w}=\int_{-\infty}^{\infty} g(x) \prod_{j \neq i} G\left(\frac{w_{i}-w_{j}}{\mu^{w}}+x\right) d x, i=1 \ldots n .
$$

- Consumer choices

The probability that a household located in the center patronizes subcenter $k$ is

$$
P_{k}^{d}=\left\{-p_{k}+\mu^{d} \eta_{k} \geq-p_{l}+\mu^{d} \eta_{l}, l=1 \ldots n\right\} .
$$

We assumed random variable $\eta$ are i.i.d., with cdf (strictly increasing and absolutely continuous) denoted by $H($.$) and density denote by h$ defined on $\mathbb{R}$. We get:

$$
P_{k}^{d}=\int_{-\infty}^{\infty} h(x) \prod_{l \neq k} H\left(\frac{p_{l}-p_{k}}{\mu^{d}}+x\right) d x, k=1 \ldots n .
$$

- Market clearing conditions

We still require that the market clearing condition holds: $P_{i}^{w}=P_{i}^{d}$, where $P_{i}^{w}$ is given by (50) and $P_{i}^{d}$ is given by (51). We get:

$$
\int_{-\infty}^{\infty} g(x) \prod_{j \neq i} G\left(\frac{w_{i}-w_{j}}{\mu^{w}}+x\right) d x=\int_{-\infty}^{\infty} h(x) \prod_{l \neq i} H\left(\frac{p_{l}-p_{i}}{\mu^{d}}+x\right) d x
$$

As before, the demand for the differentiated product sold in subcenter $i$ is $D_{i}=N P_{i}^{d}=N P_{i}^{w}$.

- The profit function

Consider the price adjustment for subcenter $i$. The LHS of (52) is strictly increasing in $w_{i}$ and the RHS is strictly decreasing in $p_{i}$ since $F$ and $G$ are strictly increasing and absolutely continuous. We denote by $r$ the one to one relation between $w_{i}$ and $p_{i}: p_{i}=r_{i}\left(w_{i}\right)$, and let $r_{i}\left(w_{i}\right)=r\left(w_{i}, w_{-i}, p_{-i}\right)$. Note that:

$\frac{d P_{i}^{w}}{d w_{i}}=(n-1) \sum \int_{-\infty}^{\infty} g(x) g\left(\frac{w_{i}-w_{j}}{\mu^{w}}+x\right) \prod_{k \neq i, j} G\left(\frac{w_{i}-w_{k}}{\mu^{w}}+x\right) d x, i=1 \ldots n$.

Therefore: 


$$
\frac{d r_{i}\left(w_{i}\right)}{d w_{i}}=-\frac{\mu^{d}}{\mu^{w}} \frac{\sum_{j \neq i} \int_{-\infty}^{\infty} g(x) g\left(\frac{w_{i}-w_{j}}{\mu^{w}}+x\right) \prod_{k \neq i, j} G\left(\frac{w_{i}-w_{k}}{\mu^{w}}+x\right) d x}{\sum_{j \neq i} \int_{-\infty}^{\infty} h(x) h\left(\frac{p_{j}-p_{i}}{\mu^{w}}+x\right) \prod_{k \neq i, j} H\left(\frac{p_{k}-p_{i}}{\mu^{w}}+x\right) d x}<0 .
$$

Note that, at the symmetric equilibrium:

$$
\frac{d P_{i}^{w}}{d w_{i} \mid S y m}=\frac{(n-1)}{\mu^{w}} \int_{-\infty}^{\infty} g^{2}(x) G^{n-2}(x) d x, i=1 \ldots n .
$$

Therefore:

$$
\frac{d r_{i}\left(w_{i}\right)}{d w_{i} \mid \text { Sym }}=-\frac{\mu^{d}}{\mu^{w}} \frac{\Gamma^{w}}{\Gamma^{d}}<0,
$$

where $\Gamma^{w}=\int_{-\infty}^{\infty} g^{2}(x) G^{n-2}(x) d x$ and $\Gamma^{d}=\int_{-\infty}^{\infty} h^{2}(x) H^{n-2}(x) d x$. The profit function is now:

$$
\widetilde{\pi}_{i}\left(w_{i}, w_{-i}, p\right)=\left[r_{i}\left(w_{i}\right)-w_{i}-c\right] N P_{i}^{w}-(F+S) .
$$

\section{B.2 Short-run equilibrium}

The best reply of subcenter $i$ is (seeing w.l.o.g. $N=1$ )

$$
\frac{d \tilde{\pi}_{i}\left(w_{i}, w_{-i}, p\right)}{d w_{i}}=\left(\frac{d r_{i}\left(w_{i}\right)}{d w_{i}}-1\right) P_{i}^{w}+\left(r_{i}\left(w_{i}\right)-w_{i}-c\right) \frac{d P_{i}^{w}}{d w_{i}} .
$$

Thus, using (55) and (55) we get:

$$
-\left(\frac{\mu^{d}}{\mu^{w}} \frac{\Gamma^{w}}{\Gamma^{d}}+1\right) \frac{1}{n}+\left(p^{e}-w^{e}-c\right) \frac{(n-1)}{\mu^{w}} \Gamma^{w}=0
$$

Or:

$$
p^{e}=c+w^{e}+\frac{1}{n(n-1)}\left(\frac{\mu^{d}}{\Gamma^{d}}+\frac{\mu^{w}}{\Gamma^{w}}\right) .
$$

Note that, for the double exponential distribution $\Gamma^{d}=\Gamma^{w}=1 / n^{2}$, then we get the formula: (17), as expected. We have therefore proved the following result:

Proposition 8 Consider a differentiated labour and product labour. with i.i.d. preferences with density function $h($.$) for the product market and g($.$) for the$ labour market Then, there exists a unique symmetric Nash equilibrium in prices and wages given by:

$p^{e}=c+w^{e}+\frac{1}{n(n-1)}\left(\frac{\mu^{d}}{\int_{-\infty}^{\infty} h^{2}(x) H^{n-2}(x) d x}+\frac{\mu^{w}}{\int_{-\infty}^{\infty} g^{2}(x) G^{n-2}(x) d x}\right)$. 


\section{B.3 Long-run equilibrium}

Note that if $n$ is log-concave, then $n(n-1) \Gamma^{d}$ is increasing is $\mathrm{n}$, as well as $n(n-1) \Gamma^{w}$ and therefore the markup $p^{e}-c-w^{e}$ is decreasing in $n$ (see [2]). As a consequence, $\pi^{e}=\frac{N\left(p^{e}-w^{e}-c\right)}{n}-(F+S)$ is decreasing at least in an hyperbolic manner and there exists a unique free entry equilibrium given by:

$$
\frac{1}{n^{2}(n-1)}\left(\frac{\mu^{d}}{\int_{-\infty}^{\infty} h^{2}(x) H^{n-2}(x) d x}+\frac{\mu^{w}}{\int_{-\infty}^{\infty} g^{2}(x) G^{n-2}(x) d x}\right)=\frac{(F+S)}{N}
$$

\section{Proof of Proposition 4}

The profit function is (where $N$ is normalized to one, w.l.o.g.):

$$
\left.\tilde{\pi}_{i}\left(w_{i}, w_{-i}, p\right)=\left[g_{i}\left(w_{i}\right)-w_{i}-c-\Lambda^{h} P_{i}^{w}\right)\right] N P_{i}^{w}-(F+S) .
$$

The first-order condition is:

$$
\frac{\partial \widetilde{\pi}_{i}\left(w_{i}, w_{-i}, p\right)}{\partial w_{i}}=\left(\frac{d g_{i}\left(w_{i}\right)}{d w_{i}}-1\right) P_{i}^{w}+\left[g_{i}\left(w_{i}\right)-w_{i}-c-2 \Lambda^{h} P_{i}^{w}\right] \frac{d P_{i}^{w}}{d w_{i}}=0 .
$$

Moreover, we have:

$$
\begin{aligned}
\frac{\partial^{2} \widetilde{\pi}_{i}\left(w_{i}, w_{-i}, p\right)}{\partial w_{i}^{2}}= & \left(\frac{d^{2} g_{i}\left(w_{i}\right)}{d w_{i}^{2}}\right) P_{i}^{w}+2\left(\frac{d g_{i}\left(w_{i}\right)}{d w_{i}}-1\right) \frac{d P_{i}^{w}}{d w_{i}}-2 \Lambda^{h}\left(\frac{d P_{i}^{w}}{d w_{i}}\right)^{2} \\
& +\left[g_{i}\left(w_{i}\right)-w_{i}-c-2 \Lambda^{h} P_{i}^{w}\right] \frac{d^{2} P_{i}^{w}}{d w_{i}^{2}}
\end{aligned}
$$

We wish to show that any turning point is a maximum:

$$
\left.\frac{\partial^{2} \widetilde{\pi}_{i}\left(w_{i}, w_{-i}, p\right)}{\partial w_{i}^{2}}\right|_{F O C}<0
$$

If this condition is satisfied everywhere, the profit function $\tilde{\pi}_{i}\left(w_{i}, w_{-i}, p\right)$ is quasi-concave, and the candidate symmetric equilibrium is Nash.

Note that, the first-order condition equation can be rewritten as:

$$
g_{i}\left(w_{i}\right)-w_{i}-c-2 \Lambda^{h} P_{i}^{w}=-\frac{\left(\frac{d g_{i}\left(w_{i}\right)}{d w_{i}}-1\right) P_{i}^{w}}{\frac{d P_{i}^{w}}{d w_{i}}} .
$$

Using this expression, we obtain after simplifications: 


$$
\begin{aligned}
\Omega \equiv & \left.\frac{d P_{i}^{w}}{d w_{i}} \frac{\partial^{2} \widetilde{\pi}_{i}\left(w_{i}, w_{-i}, p\right)}{\partial w_{i}^{2}}\right|_{F O C}=\left(-2\left(\frac{d P_{i}^{w}}{d w_{i}}\right)^{2}+P_{i}^{w} \frac{d^{2} P_{i}^{w}}{d w_{i}^{2}}\right) \\
& \times\left(1-\frac{d g_{i}\left(w_{i}\right)}{d w_{i}}\right)+\frac{d P_{i}^{w}}{d w_{i}}\left(\frac{d^{2} g_{i}\left(w_{i}\right)}{d w_{i}^{2}} P_{i}^{w}-2 \Lambda^{h}\left(\frac{d P_{i}^{w}}{d w_{i}}\right)^{2}\right) .
\end{aligned}
$$

We wish to show that this expression $\Omega$ is negative given that $d P_{i}^{w} / d w_{i}>0$. To to that, when there is no ambiguity, in order to simplify expressions, we use the following notations:

$$
\left\{\begin{array}{c}
P \equiv P_{i}^{w}=P_{i}^{d} \\
P^{\prime} \equiv \frac{d P_{i}^{w}}{d w_{i}} \\
P^{\prime \prime} \equiv \frac{d^{2} P_{i}^{w}}{d w_{i}} \\
g^{\prime} \equiv \frac{d g_{i}\left(w_{i}\right)}{d w_{i}} \\
g^{\prime \prime} \equiv \frac{d^{2} g_{i}\left(w_{i}\right)}{d w_{i}^{2}}
\end{array} .\right.
$$

Using these notations, we have equivalently:

$$
\Omega=\left(-2\left(P^{\prime}\right)^{2}+P P^{\prime \prime}\right)\left(1-g^{\prime}\right)+P^{\prime}\left(g^{\prime \prime} P-2 \Lambda^{h}\left(P^{\prime}\right)^{2}\right) .
$$

We now need to compute $P^{\prime}, P^{\prime \prime}, g^{\prime}$ and $g^{\prime \prime}$ at any point (i.e. not only at the symmetric candidate equilibrium).

First let compute $P^{\prime}$ and $P^{\prime \prime}$. Recall that

$$
P=P_{i}^{w}=\frac{\exp \left(\frac{w_{i}-\Lambda^{w} P_{i}^{w}}{\mu^{w}}\right)}{\sum_{j=1 \ldots n} \exp \left(\frac{w_{j}-\Lambda^{w} P_{j}^{w}}{\mu^{w}}\right)}
$$

We have, using again the implicit function theorem

$$
P^{\prime}=\frac{\frac{\partial P}{\partial w_{i}}}{1-\frac{\partial P}{\partial P_{i}^{w}}}=\frac{\frac{1}{\mu^{w}} P(1-P)}{1+\frac{\Lambda^{w}}{\mu^{w}} P(1-P)} .
$$

Note that:

$$
[P(1-P)]^{\prime}=(1-2 P) P^{\prime}
$$

Therefore, after simplifications, we get: 


$$
P^{\prime \prime}=\frac{\left(\frac{1}{\mu^{w}}\right)^{2} P(1-P)(1-2 P)}{\left[1+\frac{\Lambda^{w}}{\mu^{w}} P(1-P)\right]^{3}} .
$$

Second, we wish to compute $g^{\prime}$ and $g^{\prime \prime}$. Recall that the solution of the equation $P_{i}^{w}=P_{i}^{d}$ is unique and denoted by: $p_{i}=g_{i}\left(w_{i}\right)$. We have:

$$
P_{k}^{d}=\frac{\exp \left(\frac{-p_{k}-\Lambda^{d} P_{k}^{d}}{\mu^{d}}\right)}{\sum_{l=1 \ldots n} \exp \left(\frac{-p_{l}-\Lambda^{d} P_{l}^{d}}{\mu^{d}}\right)},
$$

so that, using the same reasoning as above:

$$
\frac{d P_{i}^{d}}{d p_{i}}=-\frac{\frac{1}{\mu^{d}} P_{i}^{d}\left(1-P_{i}^{d}\right)}{1+\frac{\Lambda^{d}}{\mu^{d}} P_{i}^{d}\left(1-P_{i}^{d}\right)}
$$

Differentiation of the expression $P_{i}^{w}-P_{i}^{d}=0$, as a function of $w_{i}$ leads to

$$
\frac{d P_{i}^{w}}{d w_{i}}-\frac{d P_{i}^{d}}{d p_{i}} \cdot \frac{d p_{i}}{d w_{i}}=0
$$

thus (using again the condition $P_{i}^{w}=P_{i}^{d}$ ):

$$
g^{\prime}=\frac{\frac{d P_{i}^{w}}{d w_{i}}}{\frac{d P_{i}^{d}}{d p_{i}}}=-\frac{\mu^{d}}{\mu^{w}} \frac{1+\frac{\Lambda^{d}}{\mu^{d}} P_{i}^{d}\left(1-P_{i}^{d}\right)}{1+\frac{\Lambda^{w}}{\mu^{w}} P_{i}^{w}\left(1-P_{i}^{w}\right)}<0 .
$$

Therefore:

$$
g^{\prime \prime}=-\frac{\mu^{d}}{\mu^{w}} \frac{\Phi}{\left[1+\frac{\Lambda^{w}}{\mu^{w}} P_{i}^{w}\left(1-P_{i}^{w}\right)\right]^{2}},
$$

with

$$
\begin{aligned}
\Phi= & \frac{\Lambda^{d}}{\mu^{d}}\left(1-2 P_{i}^{d}\right) \frac{d P_{i}^{d}}{d p_{i}} g^{\prime} \times\left[1+\frac{\Lambda^{w}}{\mu^{w}} P_{i}^{w}\left(1-P_{i}^{w}\right)\right] \\
& -\frac{\Lambda^{w}}{\mu^{w}}\left(1-2 P_{i}^{w}\right) \frac{d P_{i}^{w}}{d w_{i}} \times\left[1+\frac{\Lambda^{d}}{\mu^{d}} P_{i}^{d}\left(1-P_{i}^{d}\right)\right]
\end{aligned}
$$

After simplification, we get:

$$
\Phi=-\frac{1}{\mu^{w}}\left(\frac{\Lambda^{d}}{\mu^{d}}-\frac{\Lambda^{w}}{\mu^{w}}\right) \frac{(1-2 P) P(1-P)}{\left[1+\frac{\Lambda^{w}}{\mu^{w}} P(1-P)\right]}
$$


Hence, using the expression above, we obtain:

$$
g^{\prime \prime}=-\frac{\mu^{d}}{\left(\mu^{w}\right)^{2}}\left(\frac{\Lambda^{d}}{\mu^{d}}-\frac{\Lambda^{w}}{\mu^{w}}\right) \frac{(1-2 P) P(1-P)}{\left[1+\frac{\Lambda^{w}}{\mu^{w}} P(1-P)\right]^{3}} .
$$

The sign of $g^{\prime \prime}$ is ambiguous (and note that without congestion $g^{\prime \prime}=0$ ). We are now ready to sign the expression (59).

We first compute the expression $\left(-2\left(P^{\prime}\right)^{2}+P P^{\prime \prime}\right)$. We have

$$
\left(-2\left(P^{\prime}\right)^{2}+P P^{\prime \prime}\right)=-\frac{P^{2}(1-P)}{\left(\mu^{w}\right)^{2}\left[1+\frac{\Lambda^{w}}{\mu^{w}} P(1-P)\right]^{3}}\left[1+2 \frac{\Lambda^{w}}{\mu^{w}} P(1-P)^{2}\right]<0 .
$$

Furthermore, replacing the expression for $g^{\prime}$ and after simplifications, we get:

$$
\left(1-g^{\prime}\right)=\frac{\left(1+\frac{\mu^{d}}{\mu^{w}}\right)+\frac{\left(\Lambda^{w}+\Lambda^{d}\right)}{\mu^{w}} P(1-P)}{1+\frac{\Lambda^{w}}{\mu^{w}} P(1-P)}>0 .
$$

A combination of the last two expressions leads to:

$$
\begin{aligned}
\left(-2\left(P^{\prime}\right)^{2}+P P^{\prime \prime}\right)\left(1-g^{\prime}\right)= & -\frac{P^{2}(1-P)}{\left(\mu^{w}\right)^{2}\left[1+\frac{\Lambda^{w}}{\mu^{w}} P(1-P)\right]^{4}}\left[1+2 \frac{\Lambda^{w}}{\mu^{w}} P(1-P)^{2}\right] \\
& \times\left[\left(1+\frac{\mu^{d}}{\mu^{w}}\right)+\frac{\left(\Lambda^{w}+\Lambda^{d}\right)}{\mu^{w}} P(1-P)\right] .
\end{aligned}
$$

We are ready to compute the second term of (59). After substitution, we obtain:

$$
P^{\prime} g^{\prime \prime} P=-\frac{\mu^{d}}{\left(\mu^{w}\right)^{3}}\left(\frac{\Lambda^{d}}{\mu^{d}}-\frac{\Lambda^{w}}{\mu^{w}}\right) \frac{(1-2 P) P^{3}(1-P)^{2}}{\left[1+\frac{\Lambda^{w}}{\mu^{w}} P(1-P)\right]^{4}} .
$$

Note that $\Omega=\Omega^{1}-2 \Lambda^{h}\left(P^{\prime}\right)^{3}<\Omega^{1}\left(\right.$ since $\left.P^{\prime}>0\right)$, with:

$$
\Omega^{1}=\left(-2\left(P^{\prime}\right)^{2}+P P^{\prime \prime}\right)\left(1-g^{\prime}\right)+P^{\prime} g^{\prime \prime} P .
$$

We wish to show that $\Omega^{2}<0$ with:

$$
\Omega^{1}=\frac{P^{2}(1-P)}{\left(\mu^{w}\right)^{2}\left[1+\frac{\Lambda^{w}}{\mu^{w}} P(1-P)\right]^{4}} \Omega^{2} .
$$

Using the two expressions derived above, we get: 


$$
\begin{aligned}
\Omega^{2}= & {\left[1+2 \frac{\Lambda^{w}}{\mu^{w}} P(1-P)^{2}\right]\left[\left(1+\frac{\mu^{d}}{\mu^{w}}\right)+\frac{\left(\Lambda^{w}+\Lambda^{d}\right)}{\mu^{w}} P(1-P)\right] } \\
& -\frac{\mu^{d}}{\mu^{w}}\left(\frac{\Lambda^{d}}{\mu^{d}}-\frac{\Lambda^{w}}{\mu^{w}}\right)(1-2 P) P(1-P) .
\end{aligned}
$$

We can expand and regroup the terms to get:

$$
\begin{aligned}
\Omega^{2}= & -2 \frac{\Lambda^{d}}{\mu^{w}} P(1-P)^{2}-\frac{\mu^{d} \Lambda^{w}}{\left(\mu^{w}\right)^{2}} P(1-P)-\left(1+\frac{\mu^{d}}{\mu^{w}}\right) \\
& -\frac{\Lambda^{w}}{\mu^{w}} P(1-P)[1+2(1-P)]-2 \frac{\Lambda^{w}\left(\Lambda^{w}+\Lambda^{d}\right)}{\left(\mu^{w}\right)^{2}} P^{2}(1-P)^{3} .
\end{aligned}
$$

This shows, as required, that $\Omega^{2}<0$ and therefore $\Omega^{1}$ and $\Omega<0$. As a consequence:

$$
\left.\frac{\partial^{2} \widetilde{\pi}_{i}\left(w_{i}, w_{-i}, p\right)}{\partial w_{i}^{2}}\right|_{F O C}<0 .
$$

Q.E.D. 
The Center for Economic Studies (CES) is the research division of the Department of Economics of the Katholieke Universiteit Leuven. The CES research department employs some 100 people. The division Energy, Transport \& Environment (ETE) currently consists of about 15 full time researchers. The general aim of ETE is to apply state of the art economic theory to current policy issues at the Flemish, Belgian and European level. An important asset of ETE is its extensive portfolio of numerical partial and general equilibrium models for the assessment of transport, energy and environmental policies.

\section{ETE WORKING PAPER SERIES 2004}

$N^{\circ} 2004-09$

$N^{\circ} 2004-08$

$N^{\circ} 2004-07$

$N^{\circ} 2004-06$

n²004-05

$n^{\circ} 2004-04$

$n^{\circ} 2004-03$

$n^{\circ} 2004-02$

n²004-01 de Palma A., Proost S. (2004) Imperfect competition and congestion in the City

Pepermans G., Willems B. (2004), Ramsey Pricing in a Congested Network with Market Power in Generation: A Numerical Illustration for Belgium

Delhaye E. (2004), Traffic safety: speed limits, strict liability and a km tax

Eyckmans J., Finus M. (2004), An Empirical Assessment of Measures to Enhance the Success of Global Climate Treaties

Eyckmans J., Meynaerts E., Ochelen S. (2004), The Environmental Costing Model: a tool for more efficient environmental policymaking in Flanders

Saveyn B., Proost S. (2004), Environmental Tax Reform with Vertical Tax Externalities in a Federal State

Rousseau S. (2004), Timing of environmental inspections: Survival of the compliant

Knockaert J., Proost S., Van Regemorter D. (2004), Analysis of transport policy scenarios for EU-countries with PRIMEStransport

Franckx L., de Vries F.P. (2004), Environmental Liability and Organizational Structure

\section{ETE WORKING PAPER SERIES 2003}

$n^{\circ} 2003-19$

$n^{\circ} 2003-18$
Coenen G. (2003), Welfare maximizing emission permit allocations under constraints

Eyckmans J., Finus M. (2003), New Roads to International Environmental Agreements: The Case of Global Warming* 